\title{
BMJ Open Why are epilepsy mortality rates rising in the United States? A population- based multiple cause-of-death study
}

Christopher M DeGiorgio (D) , ${ }^{1}$ Ashley Curtis, ${ }^{1}$ Armen Carapetian, ${ }^{1}$ Dominic Hovsepian, ${ }^{2}$ Anusha Krishnadasan, ${ }^{3}$ Daniela Markovic ${ }^{1}$
To cite: DeGiorgio CM, Curtis $\mathrm{A}$, Carapetian A, et al. Why are epilepsy mortality rates rising in the United States? A populationbased multiple cause-ofdeath study. BMJ Open 2020;10:e035767. doi:10.1136/ bmjopen-2019-035767

- Prepublication history for this paper is available online. To view these files, please visit the journal online (http://dx.doi org/10.1136/bmjopen-2019035767).

Received 14 November 2019 Revised 06 April 2020 Accepted 10 June 2020
Check for updates

(c) Author(s) (or their employer(s)) 2020. Re-use permitted under CC BY-NC. No commercial re-use. See rights and permissions. Published by BMJ.

${ }^{1}$ David Geffen-UCLA School of Medicine, Los Angeles, California, USA

${ }^{2}$ Department of Neurology, Stanford University School of Medicine, Stanford, California, USA

${ }^{3}$ Emergency Medicine, UCLA, Los Angeles, California, USA

Correspondence to Dr Christopher M DeGiorgio; cmd@mednet.ucla.edu

\section{ABSTRACT}

Introduction Epilepsy mortality rates are rising. It is unknown whether rates are rising due to an increase in epilepsy prevalence, changes in epilepsy causes of death, increase in the lethality or epilepsy or failures of treatment. To address these questions, we compare epilepsy mortality rates in the USA with all-cause and all-neurological mortality for the years 1999 to 2017.

Objectives To determine changes in US epilepsy mortality rates versus all-cause mortality, and to evaluate changes in the leading causes of death in people with epilepsy. Design Retrospective population-based multiple causeof-death study.

Primary outcome Change in age-adjusted epilepsy mortality rates compared with mortality rates for all-cause and all-neurological mortality.

Secondary outcome Changes in the leading causes of death in epilepsy.

Results From 1999 to 2017, epilepsy mortality rates in the USA increased $98.8 \%$, from 5.83 per million in 1999 to 11.59 per million $(95 \% \mathrm{Cl} 88.2 \%-110.0 \%)$, while allcause mortality declined $16.4 \%$ from 8756.34 per million to 7319.17 per million $(95 \% \mathrm{Cl} 16.3 \%$ to $16.6 \%)$. For the same period, all-neurological mortality increased $80.8 \%$ from 309.21 to 558.97 per million (95\% Cl $79.4 \%-82.1 \%$ ). The proportion of people with epilepsy who died due to neoplasms, vascular dementia and Alzheimer's increased by $52.3 \%, 210.1 \%$ and $216.8 \%$, respectively. During the same period, the proportion who died due to epilepsy declined $27.1 \%$, while ischaemic heart disease as a cause of death fell $42.6 \%(p<0.001)$.

Conclusions Epilepsy mortality rates in the USA increased significantly from 1999 to 2017. Likely causes include increases in all-neurological mortality, increased epilepsy prevalence and changes in the underlying causes of death in epilepsy, led by increases in vascular dementia and Alzheimer's. An important finding is that ischaemic heart disease and epilepsy itself are declining as underlying causes of death in people with epilepsy.

\section{INTRODUCTION}

People with epilepsy are at higher risk for premature death. ${ }^{1}$ Nelligan et $a{ }^{1}{ }^{1}$ in a large prospective cohort study of newly diagnosed epilepsy, found that people with epilepsy had a standardised mortality rate of 2.55 , significantly higher than expected from the

\section{Strengths and limitations of this study}

Large population-based study of epilepsy mortality, using the Centers for Disease Control multiple cause-of-death database.

- Comparison between epilepsy mortality, all-cause and all-neurological mortality.

- Study reports change in the seven leading causes of death in epilepsy.

- Death certificates may under-report epilepsyrelated mortality.

- Physicians completing death certificates may not be able to fully discern the underlying and contributing causes of death

general population. Recent data from the USA and Great Britain (UK) indicate that epilepsy mortality rates are rising significantly. ${ }^{2}{ }^{3}$ Greenlund $e t a l^{2}$ reported that epilepsy mortality rates in the USA increased 47\% between 2005 and 2014. Similarly, Public Health England reported epilepsy mortality rates in the UK increased 33\% between 2003 and 2014. ${ }^{3}$ Globally, epilepsy deaths have increased $18.9 \%$ from 1990 to 2015 , while the worldwide prevalence of epilepsy increased $39.2 \%{ }^{4}$ These reports have generated significant concern from stakeholders and advocacy groups that the increase in epilepsy mortality may represent a failure to effectively treat epilepsy and prevent premature death. ${ }^{5}$

The underlying causes for the increase in epilepsy mortality rates in the USA are poorly understood and raise several questions. How is epilepsy mortality changing in comparison to all-cause mortality and all-neurological mortality? Are rising epilepsy mortality rates a result of an increase in epilepsy prevalence? Could changes in the underlying causes of death in people with epilepsy contribute to the increase in epilepsy mortality rates? Is the lethality of epilepsy increasing? Is this increasing mortality due to failure to 
effectively treat epilepsy or address preventable causes of death?

To address these questions, we analysed vital statistics data obtained from the Centers for Disease Control (CDC) multiple cause-of-death database. ${ }^{7}$ We compare changes in epilepsy mortality rates with all-cause mortality, allneurological mortality and mortality of major neurological diseases over the years 1999 to 2017. We also report and analyse changes in the underlying causes of death in people with epilepsy.

\section{METHODS}

This is a retrospective population-based multiple causeof-death study using the CDC wide-ranging online database (CDC Wonder). CDC Wonder compiles causeof-death data based on information reported on death certificates. ${ }^{7}$ This information is then coded and aggregated at the county level. The CDC Wonder Database was accessed for the years 1999 to $2017 .^{78}$ These years were selected to provide the longest contiguous period for which the same International Classification of Diseases codes (ICD-10) were utilised. The CDC migrated to the ICD-10 classification in 1999. County health departments and CDC coded all data from 1999 to 2017 with the same ICD-10 system. The multiple cause-of-death database was utilised for this study. ${ }^{78}$ The multiple cause-of-death database reports the underlying cause of death plus up to 20 contributing conditions listed on the death certificate. In the case of epilepsy, epilepsy or another cause (myocardial infarction, stroke, accidental death, etc) may be identified as the underlying or associated cause of death. Multiple cause-of-death mortality rates better reflect the complex constellation of conditions that contributed to death rather than a single cause-of-death analysis. ${ }^{9}$

The primary outcomes of this study are the following: change in age-adjusted epilepsy mortality rates compared with mortality rates for all-causes, all-neurological disorders, stroke and degenerative dementia (Alzheimer's). Secondary outcomes include changes in the seven leading underlying causes of death in epilepsy. The number of deaths per year, crude death rates, age-adjusted death rates and standard errors were obtained. Mortality rates were calculated as the number of deaths per 1000000 . For measures of variability, standard errors were utilised. Data were exported to a text file and transferred to an Excel spreadsheet (2013 version) for statistical analysis.

\section{Statistical analysis}

Age-adjusted rate ratios were computed by dividing the age-adjusted rate for year 2017 by the corresponding rate for year 1999. To calculate the statistical significance for the standardised rate ratios, we used approximate formulas by Smith. ${ }^{10}$ In addition, the weighted linear regression model was used to compute the per cent changes per year (slope) in age-adjusted mortality rates for a given cause, and the corresponding slopes were compared under the weighted linear regression model. ${ }^{11}$
We used the weighted linear regression model with piecewise linear splines to assess whether the per cent change in epilepsy mortality per year differed before and after year 2010. The per cent changes per year in epilepsy mortality for underlying cause-of-death versus epilepsy mortality using the multiple cause-of-death was compared under the regression model. The above models were weighted by the inverse of the variance estimates for the age-adjusted mortality rates. The underlying causes of death among people who died from epilepsy were compared between years 1999, 2008 and 2017 using the Cochran-Armitage test for trend, taking into account the overall trend over time and ensuring that the results would not be influenced by outliers. Level of significance was defined as $\mathrm{p}<0.05$.

\section{Patient and public involvement}

Patients and/or the public were not involved in the design, or conduct, or reporting or dissemination plans of this research.

\section{RESULTS}

Table 1 summarises changes in age-adjusted mortality rates from 1999 to 2017 for all causes, all neurological disorders, stroke, central nervous system (CNS) degenerative disorders (Alzheimer's) and epilepsy. Note that during the study period, mortality rates for all causes and stroke declined, while the mortality rates for epilepsy, all neurological disorders and degenerative dementia increased significantly, $\mathrm{p}<0.001$ (table 1 ).

\section{Epilepsy mortality: multiple cause-of-death database}

In 2017 there were 4131 deaths with epilepsy as either the underlying cause of death or 1 of 20 contributing causes, for an age-adjusted mortality of 11.59 per million (SE 0.18). Compared with 1999, the multiple cause-of-death mortality rate in 2017 increased by $98.8 \%$ (95\% CI $88.2 \%$ to $110.0 \%, \mathrm{p}<0.001)$. For the period 1999 to 2010, epilepsy multiple cause-of-death mortality increased by only $0.4 \%$ per year ( $95 \% \mathrm{CI}-0.3 \%$ to $1.1 \% \%, \mathrm{p}=0.26)$. From 2010 to 2017, epilepsy multiple cause-of-death mortality increased $9.7 \%$ per year (95\% CI $8.4 \%$ to $11.0 \%, \mathrm{p}<0.001)$. When compared with all-cause mortality for 2017, the epilepsy multiple cause-of-death mortality rate was equal to $0.06 \%$ of all-cause mortality. Figure 1 displays the changes in ageadjusted mortality for the years 1999 to 2017 . The slopes for two periods 1999-2010 and 2010-2017 were significantly different $(\mathrm{p}=0.001)$.

\section{Leading causes of death in people with epilepsy}

Table 2 summarises the leading causes of death in people with epilepsy for the years 1999 and 2017 using the multiple cause-of-death database. Of the 4131 deaths in people with epilepsy in 2017, only 1578 (38.2\%) were directly due to epilepsy itself, while 2553 (61.8\%) deaths were due to the other leading causes. When compared with 1999, the proportion of deaths as a direct result of 
Table 1 Changes in age-adjusted mortality rates 1999 to 2017 for major causes of death in the USA

\begin{tabular}{|c|c|c|c|c|c|c|}
\hline & ICD-10 code & $\begin{array}{l}1999 \\
\text { Age-adjusted } \\
\text { mortality rate } \\
\text { per million }\end{array}$ & $\begin{array}{l}2017 \\
\text { Age-adjusted } \\
\text { mortality rate } \\
\text { per million }\end{array}$ & $\begin{array}{l}\text { Per cent change, } \\
95 \% \mathrm{Cl}\end{array}$ & $P$ value & $\begin{array}{l}\text { Per cent } \\
\text { change } \\
\text { per year }\end{array}$ \\
\hline All-cause mortality & & 8756.34 & 7319.17 & $\begin{array}{l}-16.4 \%, \\
16.3 \% \text { to } 16.6 \%\end{array}$ & $<0.001$ & $<0.001$ \\
\hline Stroke & $160-169$ & 616.03 & 375.90 & $\begin{array}{l}-39.0 \%, \\
38.5 \% \text { to } 39.4 \%\end{array}$ & $<0.001$ & $<0.001$ \\
\hline $\begin{array}{l}\text { Degenerative } \\
\text { disorders of the CNS }\end{array}$ & G30-G31 & 168.90 & 367.58 & $\begin{array}{l}+117.6 \%, \\
115.5 \% \text { to } 119.7 \%\end{array}$ & $<0.001$ & $<0.046$ \\
\hline $\begin{array}{l}\text { Epilepsy: } \\
\text { multiple cause of } \\
\text { death }\end{array}$ & G40.0-G40.9 & 5.83 & 11.59 & $\begin{array}{l}+98.8 \% \\
88.2 \% \text { to } 110.0 \%\end{array}$ & $<0.001$ & $<0.001$ \\
\hline
\end{tabular}

Rates are expressed as number per million. Mortality per cent changes per year were evaluated using the weighted linear regression model; approximate formulas by Smith et al. ${ }^{10}$

CNS, central nervous system; ICD, International Classification of Diseases.

epilepsy declined from $52.4 \%$ to $38.2 \%$, for a net reduction of $27.1 \%(p<0.001)$. Malignant neoplasms, degenerative dementia (Alzheimer's) and organic mental disorders (vascular dementia and delirium) increased by $52.3 \%, 216.8 \%$ and $210.1 \%$, respectively. Ischaemic heart disease as a cause of death in people with epilepsy declined $42.6 \%$ (table 2 ).

\section{DISCUSSION}

Epilepsy age-adjusted mortality rates in the USA increased $98.8 \%$, from 5.83 per million in 1999 to 11.59 per million in 2017, $\mathrm{p}=0.001$. (figure 1). However, epilepsy was a rare cause of death, representing only $0.13 \%$ of all-cause mortality in 2017.

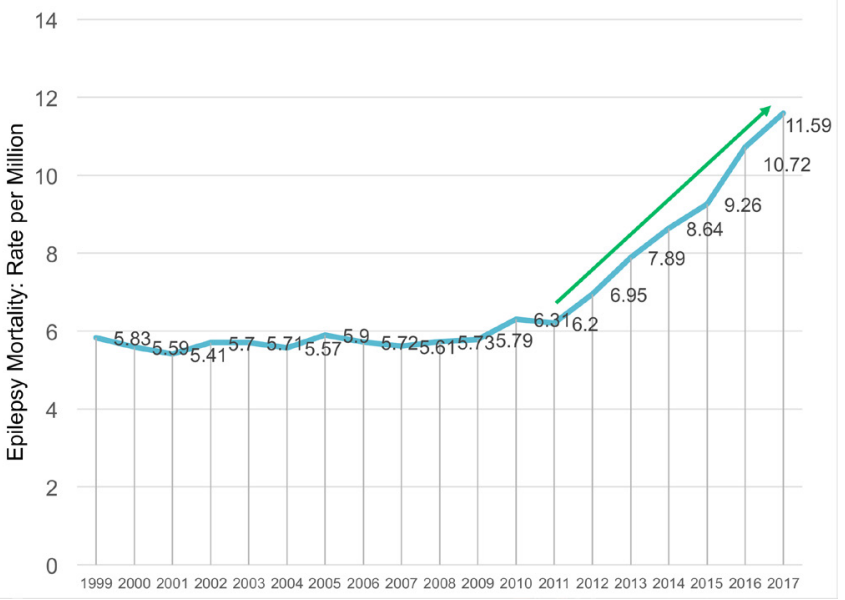

Figure 1 Epilepsy age-adjusted mortality rates, 1999 to 2017: multiple cause-of-death mortality rates. Rates are expressed as number per million. The change in slope from 2010 to 2017 was significantly increased compared with 1999 to 2009 (weighted linear regression model with piecewise linear splines, $\mathrm{p}=0.001$ ).
Three key factors may be contributing to the increase in epilepsy mortality rates from 1999 to 2017. First, the crude number of deaths due to all neurological disorders, of which epilepsy is a subset, increased from 84077 in 1999 to 216352 in 2017. The age-adjusted mortality rate for allneurological causes increased $80.8 \%$ (95\% CI $79.4 \%$ to $82.1 \%, \mathrm{p}<0.001)$. Neurological disorders are the leading cause of disability in the world, and the global burden of neurological disease is rising due to population growth and ageing. ${ }^{4}$ Epilepsy contributes to up to $25 \%$ of the global burden of neurological disease and many neurological diseases are associated with seizures and epilepsy. ${ }^{4}$ Given the association between epilepsy and neurological disorders, the increased burden and mortality of allneurological disorders are likely major contributors to the increase in epilepsy mortality rates reported here.

A second cause for the increase in epilepsy mortality rates is an increase in the prevalence of epilepsy in the USA. For the period 2010-2015, the CDC reported that the number of adults with epilepsy increased from 2.3 million to 3.0 million, and the number of children with epilepsy increased to 470000 , for an overall epilepsy prevalence of $1.2 \%{ }^{12}$ This represents a $30.4 \%$ increase in epilepsy prevalence in 2010 to $2015 .{ }^{12}$ For the same 5-year period, epilepsy underlying cause-of-death mortality rates increased $49.2 \%$ (figure 1), similar in magnitude to the $30.4 \%$ increase in prevalence reported by the CDC. ${ }^{12}$ Given the increase in both mortality rates and prevalence, we hypothesise that an increase in epilepsy prevalence is contributing to the increase in epilepsy mortality rates. The CDC states 'The increase [in epilepsy prevalence] is likely because of population growth over the past decade, or other unknown factors (eg, an increased willingness to disclose one has epilepsy). ${ }^{12}$ Immigration from regions where epilepsy prevalence is high, such as Latin America may also contribute to the increase in prevalence of epilepsy in the USA. In Latin America, reported epilepsy prevalence ranges 
Table 2 Underlying Causes of death in people With epilepsy 1999-2017

\begin{tabular}{|c|c|c|c|c|c|c|c|}
\hline \multirow{2}{*}{\multicolumn{3}{|c|}{ All deaths in people with epilepsy }} & 1999 & 2008 & 2017 & \multirow[b]{2}{*}{ Per cent change } & \multirow[b]{2}{*}{$P$ value } \\
\hline & & & 1613 & 1786 & 4131 & & \\
\hline Rank & Underlying cause of death & ICD-10 codes & \multicolumn{5}{|c|}{ Number and proportion of deaths due to the underlying cause } \\
\hline 2 & Malignant neoplasms & $\mathrm{C} 00-\mathrm{C} 97$ & $91(5.64 \%)$ & $83(4.64 \%)$ & $355(8.59 \%)$ & $+52.3 \%$ & $<0.001$ \\
\hline 3 & Cerebrovascular disease & $160-169$ & $105(6.51 \%)$ & $120(6.72 \%)$ & $284(6.87 \%)$ & $+5.5 \%$ & 0.62 \\
\hline 5 & $\begin{array}{l}\text { Degenerative diseases of the } \\
\text { CNS (ie, Alzheimer's) }\end{array}$ & G30-G31 & 24 (1.49\%) & 55 (3.08\%) & $195(4.72 \%)$ & $+216.8 \%$ & $<0.001$ \\
\hline 6 & Cerebral palsy & G80-G83 & $28(1.74 \%)$ & 52 (2.91\%) & 149 (3.61\%) & $+107.5 \%$ & $<0.001$ \\
\hline 7 & $\begin{array}{l}\text { Organic mental disorders } \\
\text { (vascular dementia and } \\
\text { delirium) }\end{array}$ & F01-F09 & $16(0.99 \%)$ & 35 (1.95\%) & 127 (3.07\%) & $+210.1 \%$ & $<0.001$ \\
\hline
\end{tabular}

Data are expressed as the number and proportion of deaths due to the underlying cause, Cochran-Armitage test for trend. CNS, central nervous system; ICD, International Classification of Diseases.

from $1.58 \%$ to $1.78 \%$, which is higher than the USA prevalence of $1.2 \% .^{1314}$

A third factor contributing to the increase in epilepsy mortality in the USA is a significant change in the underlying causes of death in epilepsy. An unexpected finding is that epilepsy as the underlying cause of death declined significantly from $52.4 \%$ of all epilepsy-related deaths in 1999 to $38.2 \%$ in $2017(\mathrm{p}<0.0001)$. This finding provides strong evidence against an increase in the lethality of epilepsy as a driver of increased epilepsy mortality. This is consistent with the observation by Neligan et al who found that the leading causes of death in people with epilepsy in the UK were not epilepsy related. Rather, cancer, cerebrovascular disease, pneumonia and ischaemic heart disease were the leading causes of death in people with epilepsy. Deaths directly due to epilepsy were rare. Comorbidities like Alzheimer's and organic mental disorders (vascular dementia and delirium) are increasing significantly in people with epilepsy in the USA

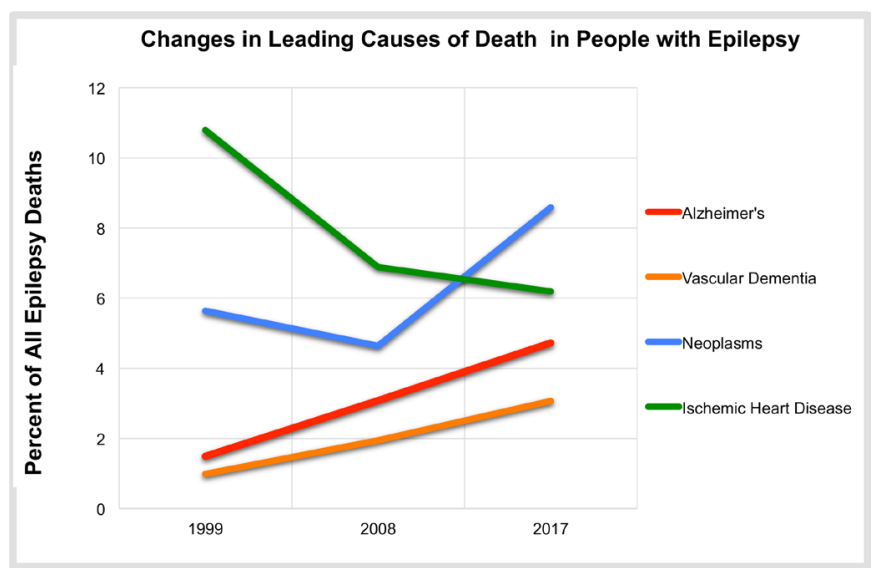

Figure 2 Relative change in key leading causes of death, 1999 to 2017. Note the significant reduction in heart disease as a leading cause of death in epilepsy, and increase in Alzheimer's, Vascular Dementia, and Neoplasms, Cochran Armitage Test for Trend, $\mathrm{p}<0.001$. (table 2 and figure 2). The proportion of deaths in people with epilepsy due to vascular dementia and Alzheimer's increased to $210.1 \%$ and $216.8 \%$, respectively. This is higher than the increase in dementia mortality in the general population reported in table $1(117.6 \%)$. Epilepsy affects $7 \%$ of the elderly, and $4 \%-5 \%$ of persons with Alzheimer's disease. These rates are substantially higher than the $1.2 \%$ in the general population. ${ }^{1516}$ At the same time, the prevalence of Alzheimer's in people with epilepsy is six times higher than those without epilepsy. ${ }^{17}$ As the population ages and the global burden of neurologic disease increases, dementia will likely continue to grow as a comorbidity and cause of death in people with epilepsy, contributing to an increase in epilepsy mortality rates in the future. ${ }^{5}$

For neoplasms, there is strong evidence that systemic cancer is associated with a high lifetime risk of epilepsy, especially in those with brain metastasis and primary neoplasms. ${ }^{18} 19$ As survival in systemic cancers increase and mortality rates decrease, it is reasonable to conclude that more survivors will develop epilepsy as a consequence of CNS involvement with cancer (table 2 and figure 2). ${ }^{18}$

An important and unexpected finding of this study is the significant decline in heart disease as a leading cause of death in epilepsy (table 2 and figure 2). Ischaemic heart disease as a cause of death in people with epilepsy declined $43 \%$ from 1999 to 2017. The reduction in heart disease mortality in epilepsy is even better than that reported in the general population, which was $22 \%$ from 1990 to $2013 .{ }^{20}$ The results suggest that people with epilepsy are benefitting from the improvements in primary prevention strategies seen in the general population. ${ }^{20}$ This is an unexpected finding given the higher risk of cardiovascular disease and stroke reported in multiple large population studies. ${ }^{21}{ }^{22}$ There is evidence that older antiepileptic drugs may increase people with vascular risk factors and with epilepsy, possibly increasing the risk for stroke and heart disease. ${ }^{23-25}$ The newer antiepileptic drugs are associated with significant improvements in biomarkers 
like C-reactive protein, low-density lipoproteins and homocysteine when compared with older agents such as carbamazepine. ${ }^{23-25}$ Many of these new agents (eg, Levetiracetam, Lacosamide) were introduced since 1999, the timeframe of this study. Further investigation of this important finding or a reduction in cardiovascular disease as a cause of death in epilepsy is needed..$^{21} 22$

Finally, while epilepsy mortality in the USA is increasing, the evidence for status epilepticus is more nuanced. ${ }^{26-28}$ The incidence of status epilepticus has increased fourfold over the last 30 years. ${ }^{26}$ However, the mortality rate of status epilepticus has remained unchanged. ${ }^{26-28}$ The stability of status epilepticus mortality in the face of rising incidence is likely due to earlier recognition and treatment, better diagnosis and coding and more effective treatment algorithms. ${ }^{26-28}$

\section{Limitations and strengths of this study}

Limitations: this study relies on mortality rates calculated from death certificates. Death certificates likely underreport epilepsy-related mortality, since there may be uncertainty about the underlying mechanism of death in people with epilepsy (status epilepticus, sudden unexplained death in epilepsy, hypoxia, etc). Data from Bell et $a l^{29}$ indicate that death certificates can significantly underestimate the number of deaths in epilepsy. For this reason, we utilised the multiple cause-of-death database, rather than the single underlying cause-of-death database. $^{7-9} 29$ When using the single underlying cause-ofdeath database, epilepsy mortality rate in 2017 was only 4.6 per million compared with 11.56 per million when using the multiple cause-of-death database. ${ }^{8}$ In a recent position paper, the National Association of Medical Examiners state:

The investigation and certification of deaths in patients with seizures and epilepsy vary within and between medical examiners' and coroners' offices. This variation, together with varied terms and criteria to diagnose and classify seizures and epilepsies...challenges the determination of cause of death (COD) in seizure and epilepsy-related death, and likely underestimates the frequency of these deaths. ${ }^{30}$

Strengths: strength of this study is the use of the largest vital record population database in the USA, incorporating data from all 50 states, the District of Columbia and Puerto Rico. It is likely that the multiple cause-ofdeath mortality rates reported in this study better reflect the varied and complex mechanisms of death in people with epilepsy, because it includes the 113 leading causes of death as defined by the CDC. ${ }^{7-9}{ }^{31}$ Indeed, when evaluating the impact of multiple causes of death in chronic diseases, Fedeli $e t a l^{31}$ write that multiple cause-of-death analyses allows '...more complete assessment of the burden of mortality related to chronic diseases but are also useful to monitor patterns and inconsistencies in cause of death certification'.

\section{CONCLUSIONS}

Epilepsy mortality rates in the USA increased significantly from 1999 to 2017. The results from this large US population-based multiple cause-of-death study indicate the increases in epilepsy mortality rates are likely caused by at least three factors: (1) increased all-neurological mortality, which is related to the increase in the burden of neurological disorders overall; (2) increased epilepsy prevalence in the USA; (3) significant increases in degenerative dementia, vascular dementia and malignant neoplasms as causes of death in people with epilepsy. Importantly, ischaemic heart disease as a cause of death declined $42.6 \%$ while epilepsy-related causes declined $27.1 \%(\mathrm{p}=0.001)$.

Acknowledgements The authors thank Kenneth D Kochanek, Statistician, National Center for Health Statistic for his advice and assistance.

Contributors AsCu created and edited the excel spreadsheet and contributed to the literature review and manuscript. $\mathrm{DH}, \mathrm{ArCa}$ and $\mathrm{AK}$ reviewed and edited the manuscript for intellectual content. DM performed the statistical analysis and reviewed and edited the manuscript. CMdG has overall responsibility for the concept, research questions, data analysis, drafting and preparing the manuscript for publication.

Funding Supported by an unrestricted grant to the David Geffen School of Medicine, UCLA Department of Neurology by James and Beverly Peters and Family. The grantees had no role in the study design, data collection, interpretation of the data, writing of the report or decision to submit the paper for publication.

Competing interests None declared.

Patient consent for publication Not required.

Provenance and peer review Not commissioned; externally peer reviewed.

Data availability statement Data are available in a public, open access repository. Source data were obtained from the Centers for Disease Control, Wonder Database. The database is open access, and interested parties may check the link https:// wonder.cdc.gov/. Data access is subject to certain conditions, see https://wonder. cdc.gov/ucd-icd10.html.

Open access This is an open access article distributed in accordance with the Creative Commons Attribution Non Commercial (CC BY-NC 4.0) license, which permits others to distribute, remix, adapt, build upon this work non-commercially, and license their derivative works on different terms, provided the original work is properly cited, appropriate credit is given, any changes made indicated, and the use is non-commercial. See: http://creativecommons.org/licenses/by-nc/4.0/.

ORCID iD

Christopher M DeGiorgio http://orcid.org/0000-0002-9863-9069

\section{REFERENCES}

1 Neligan A, Bell GS, Johnson AL, et al. The long-term risk of premature mortality in people with epilepsy. Brain 2011;134:388-95.

2 Greenlund SF, Croft JB, Kobau R. Epilepsy by the numbers: epilepsy deaths by age, race/ethnicity, and gender in the United States significantly increased from 2005 to 2014. Epilepsy Behav 2017;69:28-30.

3 Public Health England. Deaths associated with neurological conditions in England 2001 to 2014. Data analysis report, 2018. Available: https://assets.publishing.service.gov.uk/government/ uploads/system/uploads/attachment_data/file/683860/Deaths_ associated_with_neurological_conditions data_analysis_report.pdf

4 GBD 2015 Neurological Disorders Collaborator Group. Global, regional, and national burden of neurological disorders during 19902015: a systematic analysis for the global burden of disease study 2015. Lancet Neurol 2017;16:877-97.

5 Thornton J. Data show big rise in deaths of people with neurological disorders. BMJ 2018;360:1278:k1278.

6 Epilepsy today March 19, 2018. Available: https/www.epilepsy.org. uk/news/news/public-health-england-report-highlights-increasingrate-deaths-people-epilepsy- 68213 
7 Centers for Disease Control WONDER. Multiple Cause of Death Database. Available: https://wonder.cdc.gov/wonder/help/mcd.html

8 Centers for Disease Control and Prevention,, National Center for Health Statistics. Underlying Cause-of-death 1999-2017 on CDC wonder online database, released December, 2018. Data are from the multiple Cause-of-death files, 1999-2017, as compiled from data provided by the 57 vital statistics jurisdictions through the vital statistics cooperative program. Available: http://wonder.cdc.gov/ucdicd10.html

9 Israel RA, Rosenberg HM, Curtin LR. Analytical potential for multiple cause-of-death data. Am J Epidemiol 1986;124:161-79.

10 Smith Pet al. Comparison between registries: age-standardized rates. In: Muir C, Waterhouse J, Mack T, et al, eds. Cancer incidence in five continents. Lyon: International Agency for Research on Cancer, 1987: Vol V. p790-5.

11 Boyle P, Parkin DM. Statistical methods for registries. In: Jensen OM, Parkin DM, MacLennan R, et al, eds. Cancer registration: principle and methods. Lyon, France: IARC, 1991: pp126-58.

12 CDC Newsroom. More Americans have epilepsy than ever before. Available: https://www.cdc.gov/media/releases/2017/p0810epilepsy-prevalence.html

13 Bruno E, Bartoloni A, Zammarchi L, et al. Epilepsy and neurocysticercosis in Latin America: a systematic review and metaanalysis. PLoS Negl Trop Dis 2013;7:e2480.

14 Burneo JG, Tellez-Zenteno J, Wiebe S. Understanding the burden of epilepsy in Latin America: a systematic review of its prevalence and incidence. Epilepsy Res 2005;66:63-74.

15 Sen A, Jette N, Husain M, et al. Epilepsy in older people. The Lancet 2020;395:735-48.

16 Subota A, Pham T, Jetté N, et al. The association between dementia and epilepsy: a systematic review and meta-analysis. Epilepsia 2017;58:962-72.

17 Beghi E, Giussani G. Aging and the epidemiology of epilepsy. Neuroepidemiology 2018;51:216-23.

18 Weller M, Stupp R, Wick W. Epilepsy meets cancer: when, why, and what to do about it? Lancet Oncol 2012;13:e375-82.

19 Siegel RL, Miller KD, Jemal A. Cancer statistics, 2017. CA Cancer J Clin 2017;67:7-30.
20 Mensah GA, Wei GS, Sorlie PD, et al. Decline in cardiovascular mortality: possible causes and implications. Circ Res 2017;120:366-80.

21 Janszky I, Hallqvist J, Tomson T, et al. Increased risk and worse prognosis of myocardial infarction in patients with prior hospitalization for epilepsy--the Stockholm Heart Epidemiology Program. Brain 2009;132:2798-804.

22 Chen Z, Liew D, Kwan P. Excess mortality and hospitalized morbidity in newly treated epilepsy patients. Neurology 2016;87:718-25.

23 Mintzer S, Skidmore CT, Abidin CJ, et al. Effects of antiepileptic drugs on lipids, homocysteine, and C-reactive protein. Ann Neurol 2009;65:448-56.

24 Mintzer S, Skidmore CT, Rankin SJ, et al. Conversion from enzymeinducing antiepileptic drugs to topiramate: effects on lipids and C-reactive protein. Epilepsy Res 2012;98:88-93.

25 Mintzer S, Miller R, Shah K, et al. Long-Term effect of antiepileptic drug switch on serum lipids and C-reactive protein. Epilepsy Behav 2016;58:127-32.

26 Dham BS, Hunter K, Rincon F. The epidemiology of status epilepticus in the United States. Neurocrit Care 2014:20:476-83.

27 Betjemann JP, Lowenstein DH. Status epilepticus in adults. Lancet Neurol 2015;14:615-24.

28 Neligan A, Noyce AJ, Gosavi TD, et al. Change in mortality of generalized convulsive status epilepticus in high-income countries over time: a systematic review and meta-analysis. JAMA Neurol 2019. doi:10.1001/jamaneurol.2019.1268. [Epub ahead of print: 28 May 2019].

29 Bell GS, Gaitatzis A, Johnson AL, et al. Predictive value of death certification in the case ascertainment of epilepsy. $J$ Neurol Neurosurg Psychiatry 2004;75:1756-8.

30 Middleton O, Atherton D, Bundock E, et al. National association of medical examiners position paper: recommendations for the investigation and certification of deaths in people with epilepsy. Epilepsia 2018;59:530-43.

31 Fedeli U, Zoppini G, Goldoni CA, et al. Multiple causes of death analysis of chronic diseases: the example of diabetes. Popul Health Metr 2015;13:13-21. 